\title{
BRIDGING THE GAP BETWEEN ENVIRONMENTAL PLANNING EDUCATION AND PRACTICE
}

\author{
Z. TANG ${ }^{1}$, M.E. BURBACH ${ }^{2} \&$ T. WEI ${ }^{1}$ \\ ${ }^{1}$ Community and Regional Planning Program, University of Nebraska-Lincoln, Lincoln, NE 68588-0105, USA. \\ ${ }^{2}$ School of Natural Resources, University of Nebraska-Lincoln, Lincoln, NE 68583-0995, USA.
}

\begin{abstract}
Environmental plans provide an effective medium to examine the gaps between environmental planning education and practice. Although many studies have focused on the theories and procedures of environmental planning, few studies have directly addressed the education gaps in environmental planning practices. This paper provides a measurable approach to identify the environmental education gaps by evaluating environmental plan quality based on a set of indicators. The descriptive results indicate that major environmental education gaps exist in many region-wide, global-wide, long-term, cumulative, and strategically critical environmental elements. The regression results further highlight the factors that can reduce the gaps in environmental planning education. This study finally provides a framework of environmental planning education core courses to bridge the educational gaps.
\end{abstract}

Keywords: education, environmental planning, practice, sustainability.

\section{INTRODUCTION}

Environmental planning is not a new concept. As early as the 1920s, when planning was used for design purposes, Benton MacKaye sought ways to 'bring together conservation and community planning' [1]. In the late 1960s and 1970s, the modern environmental movement provided a great opportunity to build a nexus of two interdisciplinary areas: environmental studies and planning [2]. Since the 1990s, recent technologies, approaches, knowledge, and geographic information systems (GISs) have impacted environmental planning. Thus, environmental planning must be considered as an interdisciplinary field of practice that includes environmental studies, planning, and recent technologies, among others. Environmental planning is defined as 'the process of planning for environmental protection and problem solving' [3]. Both environmental protection and problem solving involve extensive knowledge, skills, and abilities. Thus, the complex and interdisciplinary nature of environmental planning poses serious challenges to educators.

Although recent technologies (e.g. remote sensing and GIS) and recent subspecialties (e.g. environmental justice and environmental dispute resolution) have further enriched environmental planning education [4], the main focus of current environmental planning education still emphasizes the core planning curriculum [5-11]. A recent comprehensive survey conducted by White and Mayo in 2004 developed an explanatory model for environmental planning education; however, few studies have empirically analyzed the gaps between environmental planning education and practice. Therefore, in order to achieve effective environmental planning, it is critical to identify and bridge the gaps between education and practice. Previous studies fell short when it came to detecting the gaps between education and practice and failed to provide a conceptual framework to systematically identify the critical factors associated with gaps.

The objective of this study is to detect gaps between environmental planning education and practice, and then identify the factors influencing the gaps. Specifically, this study answers the following three research questions: (1) Where are the gaps between environmental planning education and practice, and which environmental elements are receiving the least attention in current environmental plans? (2) Which factors create environmental planning gaps that actually identify the gaps in 
environmental planning education? (3) What can environmental planning education learn from existing current environmental planning?

To address current environmental planning education gaps, this study provides a conceptual framework that reflects the relationship between environmental planning education and practice (Fig. 1). Environmental planning education is a fundamental discipline for training future environmental planners. Education effectiveness is reflected in the products of environmental planning. This study analyzes environmental plans to evaluate the quality and weaknesses of current environmental plans. The descriptive results of this evaluation will provide critical feedback for environmental planning education and policy adjustment. At the same time, this study also examines which factors significantly influence environmental planning gaps and asks which ones should be considered in environmental planning education.

\subsection{Dependent variable}

The dependent variable in this study is the cumulative gap in environmental education, which is measured by the total percentage of gaps in environmental planning quality. The higher the percentage a plan receives the more the gaps a plan has. This study used local jurisdictions' environmental plans to evaluate the gaps and develop a plan evaluation framework consisting of five factors to measure the quality of each environmental plan. These factors include: (1) factual basis; (2) goals and objectives; (3) inter-organizational coordination; (4) policies, tools, and strategies; and (5) implementation and monitoring. Within each plan factor, a detailed set of indicators can be identified, measured, and compared across multiple local environmental plans to help understand the gaps between environmental planning education and practice.

\subsubsection{Factual basis}

Berke and French [12] point out that the factual basis of a local plan should identify existing local conditions and the needs for community physical development. The factual basis should address the current context of local environmental and socioeconomic settings, the driving forces behind growth and development, and outside influences that affect local planning decisions. The factual basis in a local environmental plan includes an inventory of existing conditions for the natural environment, built environment, and human health within the targeted jurisdiction. The factual basis should capture

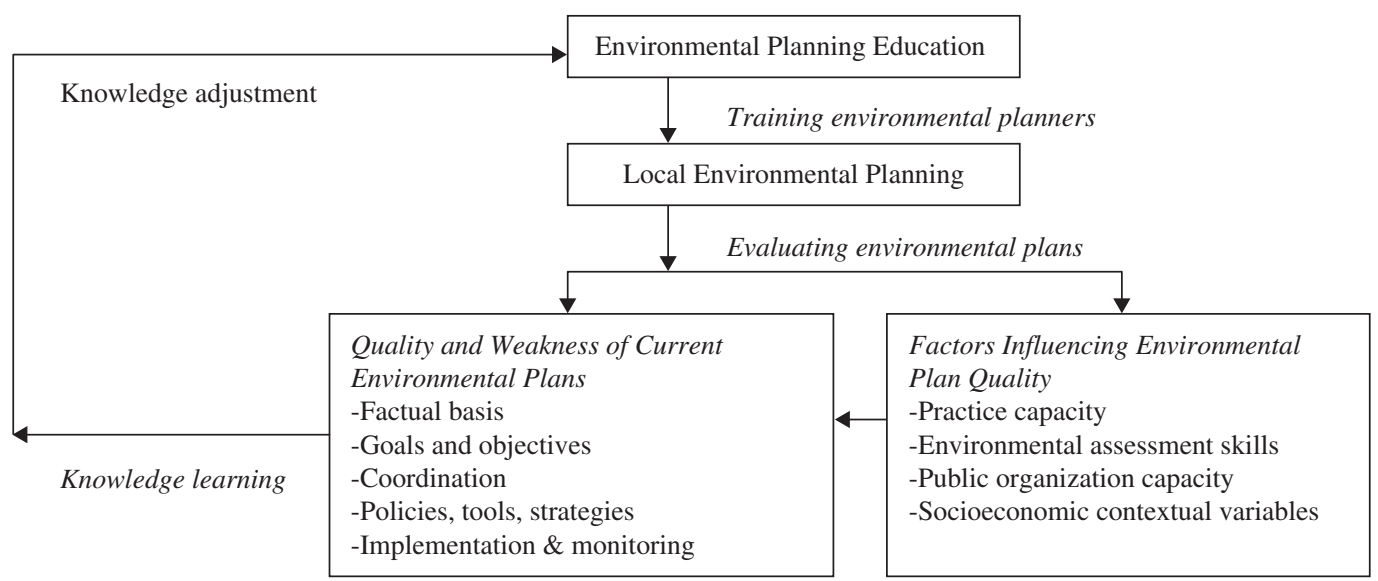

Figure 1: Conceptual framework of environmental planning education and plan quality. 
environmental conditions that significantly affect the quality of the human environment rather than just comprise a thorough checklist. The variables in the factual basis of a plan can partially examine the effectiveness of environmental education in ecological science, environmental economics, environmental impact assessment, environmental laws, and applied skills such as GIS.

\subsubsection{Goals and objectives}

For effective environmental planning, the goals and objectives should reflect the needs and desires of the local jurisdiction and indicate the actions required to achieve the envisioned future. Goals and objectives in local plans should embody the vision of what the community wants to become in the future [13], and serve as an overall policy guide for local development. Goals are general expressions of a local jurisdiction's values and may be abstract in nature; they should be long-term, challenging, consistent, and clear. The target objectives are more specific statements of planning activities required to achieve local goals, and they should be specific, measurable, acceptable, realistic, and rewarding. Goals and objectives can partially examine the effectiveness of environmental education in environmental philosophy, planning theory, and sustainability concepts.

\subsubsection{Inter-organizational coordination}

Environmental inter-organizational coordination is crucial for local environmental planning, because environmental problems are increasingly recognized as multiple-scale issues [14]. Inter-organizational coordination emphasizes that the environmental problems are complex, cross-boundary, dynamically dispersed, and multi-scale. Inter-organizational coordination serves as an umbrella framework for all the agencies providing collaborative services at the local level. It requires a wide range of expertise to understand these environmental problems, and an even wider range of agencies to seek and implement solutions. Identifying stakeholders and their inter-organizational coordination procedures can help to eliminate areas of conflict, identify locations where specific conflicts will occur or attempt to create a mechanism for conflict resolution. This component reflects the effectiveness of current dominant planning and environmental management theory involving communication and coordination.

\subsubsection{Policies, tools, and strategies}

Policies, tools, and strategies are the heart of local environmental plans, which set forth specific principles of environmental design and development management [14], and reflect clear commitments to guide decision-making in local jurisdictions. Policies, tools, and strategies should be worded, so their progress or achievement can be monitored or measured. Each of the policies, tools, and strategies may pertain to only one particular aspect of a goal or it may be one of several successive steps toward goal achievement. This plan component will reflect the effectiveness of education in adaptive environmental design, planning, and management.

\subsubsection{Implementation and monitoring}

Implementation and monitoring are planning actions necessary to implement a plan's policies, tools, and strategies [13]. A plan is a long-term visionary document, but it should include continuous reviews or updating procedures. Local environmental plans need to incorporate effective implementation and monitoring actions, so local jurisdictions can continuously monitor their plan to evaluate its success and ensure that the plan remains up to date as conditions evolve. Implementation and monitoring make it possible for a local plan to become a reality. Implementation emphasizes making policies, tools, and strategies effective, whereas monitoring focuses on changing conditions and updated standards to identify the gaps between environmental planning and application. 


\subsection{Independent variables}

Independent variables will be used to examine the factors influencing the planning gaps. This study includes four sets of variables: (1) practice capacity, (2) environmental assessment skills, (3) public organization capacity, and (4) socioeconomic context.

\subsubsection{Practice capacity}

Practice capacity addresses local environmental management through growth management, environmental assessment, hazards management, and urban design and is measured by four factors: (1) educated planners, (2) plan update date, (3) regional collaboration, and (4) GIS technical levels [14-17]. The educated planners were measured by the actual numbers on the 2005 California Planners' Book of List. The plan elements' update was calculated by using the year 2005 minus the actual year of the conservation element. Regional collaborative efforts are measured by the jurisdictions participating in regional collaborative planning efforts. The GIS technical level was measured by the GIS data adopted in the planning process.

\subsubsection{Environmental assessment skills}

Environmental assessment skills measure local ability in environmental analysis, information management, and procedure organization. It considers three factors: (1) assessment scope, (2) streamlining ability, and (3) information management and sharing [17]. Assessment scope was measured by the types of environmental assessment documents used for the last plan update. Streamlining ability was measured by the degree of streamlining environmental assessment. Information management and sharing was measured by the documents that jurisdictions regularly post on their websites.

\subsubsection{Public organization capacity}

Public organization capacity measures whether environmental planners have recognized the importance of public participation and how well they have organized the events. Environmental planning should provide a platform for mutual debate, rational consideration, reaching consensus on public issues relevant to plan decision-making, and serve as a communicative rationality for uncertainty, inequality, conflict, and a shortage of problem-solving resources. Three factors selected to analyze public participation capacity include participation formats, public notice channels, and public participation incentives [17]. Participation formats were measured by the types of workshops, townhall meetings, site tours, charrettes, and others. Public notice channels were measured by the types of information media (e.g. internet, publications in a non-English newspaper, radio, television, and others). Public participation incentives were measured by the types of incentive policies (e.g. evening meetings, providing daycare at public meetings, providing transportation for public meetings, holding public meetings near the project site, involving youth in community planning exercises, etc.).

\subsubsection{Socioeconomic context}

Socioeconomic context factors can be used to measure the influence of socioeconomic background information on planning quality. This study chooses population [18, 19], population growth [14], wealth $[20,21]$, and education [22] as the factors. Population was measured by the population in 2000 census data. The unit for population is calculated per 1000 people. Wealth is measured by the median home value in 2000 census data. The unit for population is calculated per 1000 dollars. 
Population growth is measured by population changes from 1990 to 2000; a percentage is used to describe these population changes. Education is measured by the percentage of people's ages above 25 years with bachelor degrees or higher in 2000. A percentage is used to represent different education levels. Public and conservation lands are measured by the actual percentage of public and conservation lands within a jurisdiction. The percentage of public and conservation lands within a jurisdiction is calculated from the GIS data.

\section{RESEARCH METHODS}

\subsection{Sample selection}

California is an ideal study area, because it has the most developed environmental management mandates and planning guidance. The target for this study is the environmental plans of all the plan jurisdictions in California. The sampling strategy involved the following steps: (1) the sample of local jurisdictions was limited to jurisdictions with a population of 2500 or more to avoid skewing towards small communities; (2) large metropolitan areas were excluded from the sample in order to exclude the socioeconomic contextual factors on the samples; this study excludes the traditional large jurisdictions; and (3) the sample was limited to jurisdictions within 50-mile coastal zone areas (including the coastal bay areas) to maintain a degree of consistency and comparability in terms of the types of environmental conditions assessed. Based on the above mentioned procedures, we obtained a random sample from 40 local jurisdictions that was evaluated against plan coding protocol indicators in the results section. This study scanned whole plans to evaluate environmental plan quality.

Most of the local jurisdictions' environmental plans were collected from the online service of the California Land Use Planning Information Network or local jurisdictions' planning agency web sites; some plans were requested by mail or email. All of the local jurisdictions' environmental plans were the most current version. In some circumstances, a request was made of local planning officers to get the most recently updated changes for their jurisdiction.

\subsection{Data analysis}

The plan evaluation is based on a detailed protocol. To maintain inter-subjectivity of plan evaluation, the scorer pre-tested and multiple-tested plan indicators against plan coding to reduce personal bias in measurement and improve personal experience in judgment. Each plan was evaluated three times and then the final-time score was adopted for each indicator. This study used the equal weighting approach for all of the indicators to avoid personal bias for the weighting values; however, this method unavoidably has certain limitations, because it equally counts all indicators that may over- or under-evaluate some particular variables.

\subsection{Data analysis procedures}

This research includes two stages of data analysis: first, this study uses descriptive statistics to assess the gaps in the 40 local environmental plans and second, this study used multiple regression analysis to analyze the factors influencing the gaps. The ordinary least squares technique was introduced into this study to measure the kinds of factors influencing the gaps. The reliability test shows that there was no violation of regression. 


\section{RESULTS}

\subsection{Total environmental planning gaps}

The descriptive statistics for each plan component and total environmental planning gaps are listed in Table 1. The mean of the total gaps is $52.1 \%$ on a scale of $100 \%$. The total gap score indicates that more than half of the plans did not reach a high level, which shows the environmental planning education gaps. The larger standard deviations indicate that there are large variations in environmental plan quality across local jurisdictions because each jurisdiction has different incentives and ability to address local environmental planning issues.

\subsection{Indicator gaps}

\subsubsection{Factual basis}

Factual basis shows that traditional local environmental elements have fewer gaps in current environmental plans, including open space (total gap 13.4\%), local major environmental hazards (14.1\%), noise areas $(18.3 \%)$, ecologically important areas (19.9\%), water resource $(22.0 \%)$, and vegetation and forestry resources $(24.4 \%)$. However, the largest gaps exist in climate change and variability (total gap 62.7\%), greenhouse gas emissions (58.8\%), biodiversity and disturbance and threats $(57.9 \%)$, vulnerability (54.8\%), temporal impact (52.5\%), ecosystem (50.8\%), and ozone layer depletion $(49.1 \%)$. All of these items are strategically important environmental issues, which may have cumulative impacts on the local environment on a long-term scale, but these items were not thoroughly considered in current local environmental plans. Results in this factual basis section demonstrate that local decision makers may not be fully aware of long-term, strategic, and largerscale environmental impacts. Additionally, local planning agencies may lack adequate ability to analyze region-wide, global-wide, strategic, and cumulative environmental impacts.

\subsubsection{Goals and objectives}

The results indicate that there are fewer gaps in local-based environmental goals such as disasterresistant, healthy, safe community (total gap 6.3\%), clean water $(6.4 \%)$, local natural resources $(8.1 \%)$, and accessible open space $(11.1 \%)$. By contrast, relatively larger gaps exist in the goals for biodiversity and ecosystems (41.1\%), intergenerational sustainability (45.0\%), environmental stewardship (46.3\%), and environmental justice and equity (63.8\%). Local jurisdictions mainly sought environmental goals closely related to local environmental quality (e.g. water), whereas some long-term critical environmental goals (e.g. environmental stewardship) were poorly identified in local plans.

Table 1: Descriptive statistics for environmental planning gaps.

\begin{tabular}{lcccc}
\hline Components & $\begin{array}{c}\text { Minimum } \\
(\%)\end{array}$ & $\begin{array}{c}\text { Maximum } \\
(\%)\end{array}$ & $\begin{array}{c}\text { Mean } \\
(\%)\end{array}$ & $\begin{array}{c}\text { Standard } \\
\text { deviation }(\%)\end{array}$ \\
\hline Factual basis & 20.9 & 77.4 & 54.6 & 14.1 \\
Goals and objectives & 0.00 & 76.9 & 44.2 & 17.8 \\
Inter-organizational coordination & 5.5 & 83.3 & 41.5 & 18.4 \\
Policies, tools, and strategies & 19.0 & 81.0 & 53.0 & 13.3 \\
Implementation and monitoring & 27.7 & 94.4 & 67.1 & 17.0 \\
Total gaps & 19.5 & 73.4 & 52.1 & 13.7 \\
\hline
\end{tabular}


In addition, gaps were found in linking long-term mission with practical objectives. Although a local jurisdiction's mission for environmental protection may be clear, some long-term critical environmental goals (e.g. sustainability, ecosystem and biodiversity, environmental justice, and environmental stewardship) were often omitted in local plans. Local environmental plans need to have clear strategies that develop a road map to sustainability, including specific targets for long-term environmental goals with specific objectives.

\subsubsection{Inter-organizational coordination}

Fewer gaps existed in coordination with regional agencies (total gap 6.4\%), surrounding agencies (6.5\%), and state and federal agencies (17.7\%); however, relatively larger gaps were found in local plans for committing financial support (55.6\%), or environmental conflict management procedures (39.4\%). The need for collaboration on environmental issues is well recognized by local jurisdictions in order to create a framework at the local level for strategic environmental assessment and management with other organizations $[23,24]$. The biggest problem for inter-organizational coordination arises from the lack of existing environmental information, and new approaches in cross-boundary programs are not reflected in current local environmental plans. Collaborative efforts require more attention to environmental issues with broader spatial scales or temporal impacts, particularly with respect to ecosystem-based management, biodiversity, and global warming. Each local planning agency should take responsibility to coordinate its environmental plan with other environmental planning efforts as much as possible. The lack of effective collaboration for planning policies and plans can result in poorly planned and inefficient development.

\subsubsection{Policies, tools, and strategies}

Although regulatory policies such as land use permits (total gap 6.9\%), land use restrictions (7.7\%), and sensitive land protection (15.9\%) were most frequently adopted by existing local jurisdictions; incentive tools such as preferential tax treatment (52.2\%), watershed-based and ecosystem-based land management (51.7\%), and density bonus (43.4\%) were often omitted in current environmental plans. Also, traditional environmental planning tools tend to have few gaps (e.g. trends analysis $14.8 \%$ ); however, most jurisdictions have neither the incentives nor the capacity to incorporate ecological foot print analysis (59.2\%), vulnerability analysis (62.9\%), and life cycle analysis $(72.5 \%)$ into their environmental planning. A central question for local environmental planning thus becomes how to motivate communities to protect critical environments before they are severely impacted by human growth and development. New approaches for environmental protection should be considered in existing environmental planning. Environmental planning and protection does not exist in a vacuum, and local jurisdictions need to integrate planning tools, regulatory policies, incentive tools, land acquisition programs, and communication-based policies into a whole toolbox. Other policies, tools, and strategies can be used effectively to supplement regulations and work together to provide a relatively permanent way to protect the environment.

\subsubsection{Implementation and monitoring}

Many local jurisdictions failed to give a clear, reliable time schedule (total gap 44.9\%), identify major agencies' responsibilities $(42.0 \%)$, mitigation measures $(38.8 \%)$, monitoring procedures $(30.3 \%)$, and updating procedures $(23.1 \%)$ for plan implementation and monitoring. Since an environmental plan is a long-term document, it must be regularly refreshed with new knowledge, techniques, or data as they become available to ensure that its outlook does not become outdated. Evaluating a local environmental plan's effectiveness and making course corrections relies upon the local planning agency's ability to continue introducing new information with new techniques into implementation. 
Implementation and monitoring is an essential part of local planning, which enables the plan to be a flexible policy instrument and ensures that a local environmental plan can effectively practice adaptive management $[3,25]$. Lack of strategic implementation of these policies has placed even greater pressure on open space, ecosystems, habitats, and land use management. However, local plans should provide a general roadmap with strategies for implementation and monitoring of goals and policies. Local environmental planning should be a dynamic process based on a snapshot of jurisdiction values, politics, and environmental conditions at a particular planning moment. A local environmental plan should reflect changes and continually monitor the relevance of plan elements to ensure that they remain in touch with evolving conditions.

All of these findings indicate the gaps and shortcomings in current environmental planning education. The following section explains which factor may cause these gaps.

\subsection{Factors influencing educational gaps}

This study first analyzed independent variables in each category and then identified significant variables to build a fully specified model. The results for the regression model are listed in Fig. 2 .

In the final fully specified model, the results suggest that the four variables (educated professional planners, plan age, information sharing, and population) statistically and significantly influence the cumulative environmental planning gap. The number of planners has a statistical impact on plan quality, because a greater number of planners can bring more human resources, expertise, and personnel to the local planning process. Therefore, more planners may improve environmental plan quality and reduce environmental planning gaps. The findings highlighted the importance of planners in environmental planning quality; thus environmental planning education can directly address current and future planners and inform them about critical environmental factors.

In addition, the regression results demonstrate that the more recent updated plans have statistically less environmental planning gaps than out-of-date plans. On-time, regular plan updating keeps local planners apprised of new information, conditions, regulations, and techniques, and leads to higher

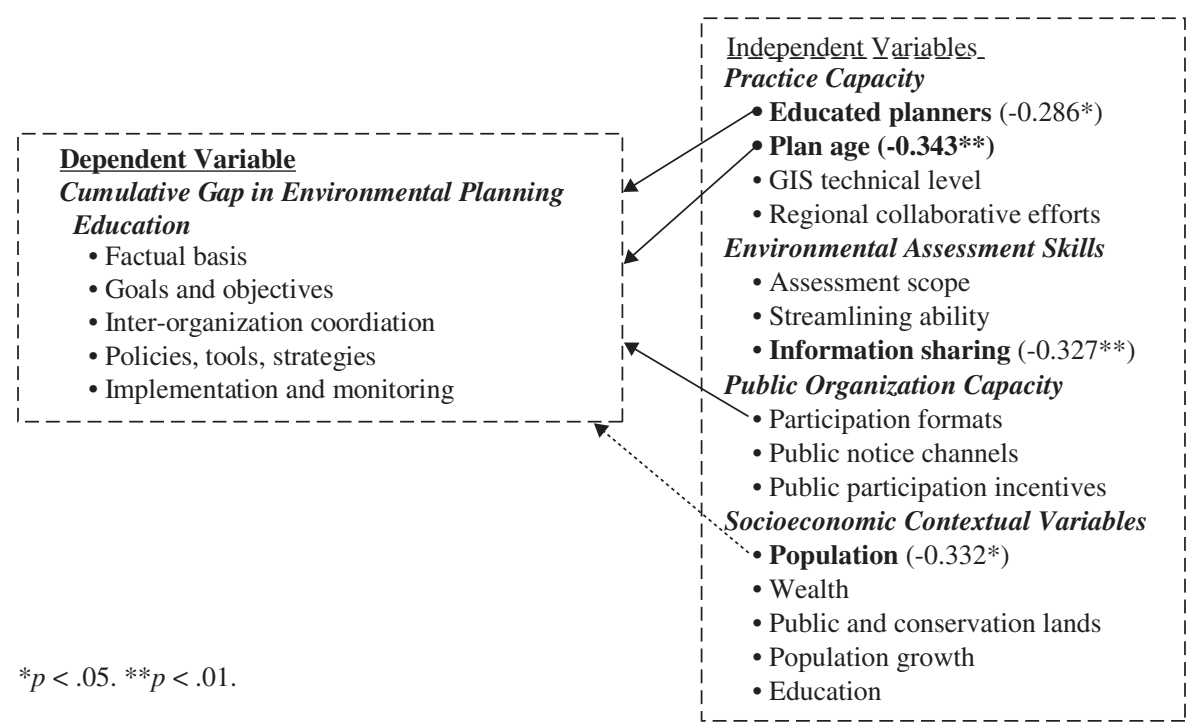

Figure 2: Factors influencing gaps in environmental planning education. 
plan quality. This finding indicates the importance of updating planning education to stress to future planners the importance of regular plan review and the need for adjustments in the planning process.

Moreover, information-sharing plays a significant role in environmental planning by promoting communication of environmental information and usage. It aids planners by improving response to complex situations.

Lastly, population is statistically significant as a contextual variable. Local jurisdictions with larger populations may have relatively more expertise and resources to conduct effective environmental planning and deal with possible environmental conflicts in the development process.

\section{CONCLUSIONS}

Regarding the first question (Where are the gaps between environmental planning education and practice, and which environmental elements are receiving the least attention in current environmental plans?), the descriptive results indicate that there are fewer environmental educational gaps in planning for local-related environmental elements (e.g. water, air, lands, etc.), but there are larger gaps in incorporating region-wide, global-wide, long-term, cumulative, and strategically critical environmental elements (e.g. impacts of globalization and climate change, ecosystems, biodiversity, greenhouse gas emission, ozone layer depletion, environmental justice) in local environmental plans. This result is consistent with some recent studies showing that strategic, large-scale environmental issues have generally been omitted in current land use planning [14-16, 26-29]. Although California has the advanced environmental planning system, the findings indicate the large educational gaps between environmental planning education and practice.

Regarding the second question (Which factors highly influence environmental planning gaps that actually identify the gaps in environmental planning education?), the results identified that the four factors (number of professional planners, planning age, information sharing, and population) are critical to reduce environmental planning gaps. First, the explanatory results suggest that greater planning capacity (i.e. professional planners, planning updating) can lead to higher quality; however, jurisdictions with understaffed planning agencies are at a distinct disadvantage when it comes to reducing the environmental planning gaps. Plan updating ability is also critical for plan quality from the explanatory results since a timely, regular plan update procedure helps local jurisdictions keep abreast of existing new information, conditions, regulations, and techniques and leads to higher quality. Indeed, environmental planners and practitioners of participatory local planning must recognize the need for life long learning and knowledge driven decisions [30-32]. The findings from the variable analysis are partially consistent with some previous studies which have highlighted the important role of planning capacity in local land use planning quality $[15,17,19]$ and the correlation between planning staff and planning updates. The previous studies have identified that planning outcomes can be improved by professional planners (e.g. mapping environmental risks, operating and maintaining computer data bases) needed by the planners [29, 33]. They handle such administrative duties as correspondence and meeting minutes, and acquiring technical resources. The findings of this study further confirm that professional member inputs, planning resources, and community support were found to be statistically significant for planning effectiveness $[29,33]$. Therefore, it becomes crucial to educate our next-generational environmental planners to be qualified environmental workers in local environmental planning and management through developing strategic and functional plans, administering environmental regulations, providing technical support, coordinating environmental personnel, and implanting environmental decisions at local levels.

Regarding the third question (What should environmental planning education learn from existing current environmental planning?), the results have identified the strengths and weaknesses of current environmental planning. The results provide an opportunity to further highlight the essentials of 
environmental planning. First, environmental planning is an interdisciplinary study that includes more than environmental sciences, planning, and technologies. Planners must recognize that environmental problems are complex requiring holistic interdisciplinary solutions [3, 34]. The interdisciplinary characteristics should be reflected in the five components of environmental plans.

Second, it is a proactive model, which should identify critical potential environmental issues and adopt advanced policies early in planning decisions. Environmental planning educators should reinforce the idea that plans must be proactive in order for development to proceed in a sustainable and environmentally sound way $[35,36]$.

Third, it is integrative environmental management that incorporates cumulative environmental impacts (e.g. biodiversity, climate change, and environmental justice) into it. To achieve sustainable development, natural resources must be managed in an integrated manner [34, 36-38].

Fourth, it is an ecosystem-based approach for planning, which emphasizes a comprehensive picture to link local environmental issues with cross-boundary scales. Environmental planning education programs must emphasize an ecosystem-based approach that melds sustainable principles with scientific methods to produce new, usable knowledge that meets socioeconomic needs while conserving natural resources and respecting limits [38-40].

Fifth, it is adaptive planning (e.g. regular plan updating, effective information sharing, and learning-based policy making) that adjusts planning activities to meet new situations. The adaptive planning approach can be one of the most effective frameworks for dealing with an evolving policy landscape [41-45].

Sixth, it is also a collaboration and implementation process that should be improved in current environmental plans. Because collaboration results in decisions that enhance environmental protection [23, 46, 47], environmental planners need to develop skills to manage collaboration. Indeed, we are reminded by Lawrence Halprin [48] 'that the techniques and processes that are required to lead or participate in a successful and rewarding collaboration be taught as part of our professional education and should become an integral part of our profession. Only then can we presume to lead or conduct large teams in the planning and design of our environment.'

Based on these essentials, this study further revises the core course model of environmental planning proposed by White and Mayo [4]. Figure 3 shows that core environmental planning education must address four aspects: (1) environmental knowledge, (2) planning knowledge, (3) technological

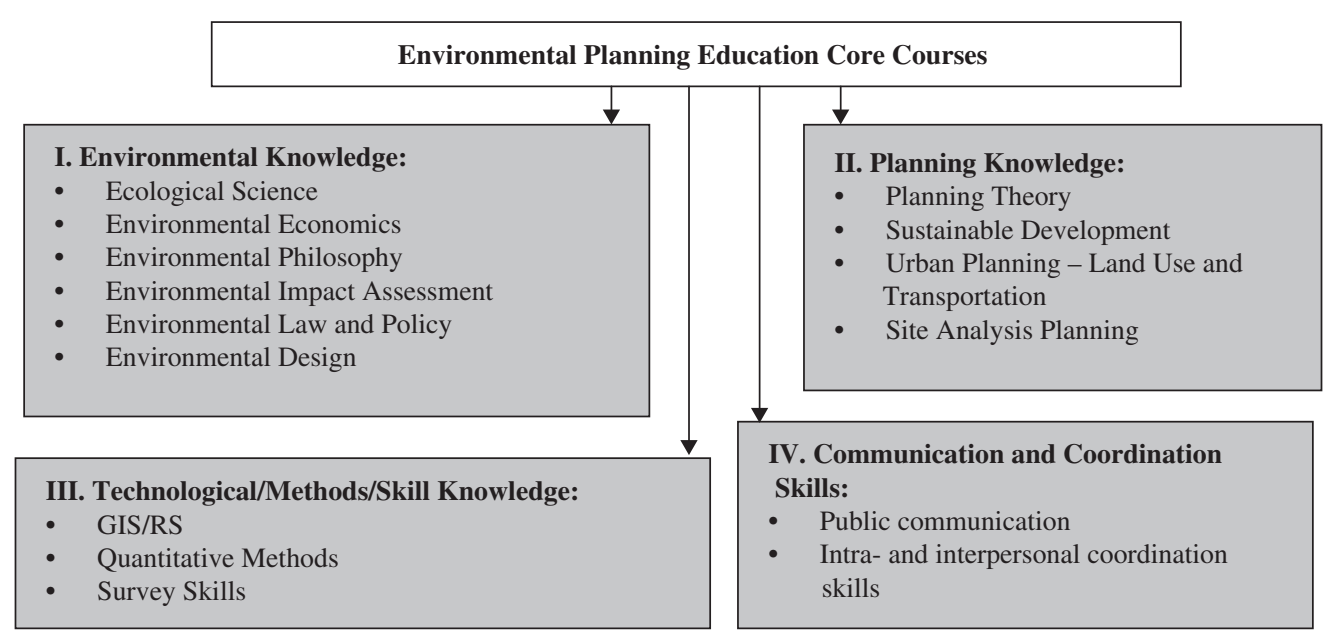

Figure 3: Environmental planning education core courses. 
knowledge, and (4) communication and coordination skills. Planners need to develop public communication skills. In addition, planners must also consider developing intra- and interpersonal skills to aid in collaboration and facets of adaptive management such as information sharing (i.e. communication skills). Future environmental planning education should incorporate these core courses to improve local environmental planning ability. Environmental planning education should build a solid factual basis, set clear goals and practical objectives, adopt appropriate new policies and tools, and establish strong mechanisms for coordination and implementation.

\section{THEORETICAL AND POLICY IMPLICATIONS}

The findings extend established rational planning theory and practice by bridging the gap between the education system and practical field. This study builds a measurable conceptual model to link practical environmental plan quality and environmental planning education. In addition, the findings further add to the theory of socio-ecological idealism [22]. This study found that cumulative, strategic environmental issues are rarely identified in existing local environmental planning, thus, the findings indicate that the theory of socio-ecological idealism still is far from becoming practice. Additionally, the findings contribute to the theory of political-economic mobilization. Environmental planning products can be improved through a better understanding of the insights afforded by explicitly considering social and environmental justice, stakeholders' conflicts, social equity, and community empowerment.

\section{LIMITATIONS AND FUTURE STUDIES}

Although this paper addresses the gaps between environmental planning education and practice, there are still some limitations. We do understand there are many issues influencing environmental plan quality, and education for the plan makers is one of the critical factors. The relatively small sample size may lack adequate statistical power to extend the findings beyond the study area. Additionally, it is a challenging issue to define the indicators as strategically critical environmental elements because many environmental elements (e.g. water, air, or even land) are dynamic and ongoing, and it is difficult to define them on a certain scale. Moreover, it is difficult to measure the impacts of external factors (e.g. geographical variations, socioeconomic characteristics, and policy framework) in the regression models. A future study will conduct a survey of environmental planners to further identify the direct links between environmental planning ability and environmental planning education. The future study also should study the influence of the existing combined land use-transportation conditions to environmental planning in some new emerging cities.

\section{ACKNOWLEDGMENTS}

The authors really appreciate anonymous reviewers for their constructive comments. This research is supported by Hyde Professorship Fund, Faculty Seed Grant, and Layman Award from University of Nebraska-Lincoln.

\section{REFERENCES}

[1] Gottlieb, R., Forcing the Spring: The Transformation of the American Environmental Movement, Island Press: Washington, DC, 1993.

[2] Godschalk, D.R., Editor's introduction. Journal of the American Institute of Planners, 37(4), p. 210, 1971.

[3] Randolph, J., Environmental Land Use Planning and Management, Island Press: Washington, DC, 2004.

[4] White, S.S. \& Mayo, J.M., Learning expectations in environmental planning. Journal of Planning Education and Research, 24, pp. 78-88, 2004. 
[5] Deknatel, C.Y., Choices of orientation in teaching environmental planning. Journal of Planning Education and Research, 3(2), pp. 118-125, 1984.

[6] Carter, E.J., Toward a core body of knowledge: a new curriculum for city and regional planners. Journal of Planning Education and Research, 12(2), pp. 160-163, 1992.

[7] Friedmann, J., The core curriculum in planning revisited. Journal of Planning Education and Research, 15(2), pp. 89-104, 1996.

[8] Baum, H.S., Social science, social work, and surgery: teaching what students need to practice planning. Journal of the American Planning Association, 63(2), pp. 179-188, 1997.

[9] Ozawa, C. \& Ethan, P.S., Taking our bearings: mapping a relationship among planning practice, theory, and education. Journal of Planning Education and Research, 18(3), pp. 257-266, 1999.

[10] Alexander, E.R., What do planners need to know? Journal of Planning Education and Research, 20(3), pp. 376-380, 2001.

[11] Seltzer, E. \& Connie, P.O., Clear signals: moving on to planning's promise. Journal of Planning Education and Research, 22(1), pp. 77-86, 2002.

[12] Berke, P.R. \& French, S.P., The influence of state planning mandates on local-plan quality. Journal of Planning Education and Research, 13, pp. 237-250, 1994.

[13] Tang, Z., Lindell, M., Prater, C. \& Brody, S.D., Measuring tsunami hazard planning capacity on the U.S. Pacific coast. Natural Hazards Review, 9(2), pp. 91-100, 2008a.

[14] Brody, S.D., Carrasco, V. \& Highfield, W., Evaluating ecosystem management capabilities at the local level in Florida: identifying policy gaps using geographic information systems. Environmental Management, pp. 32, pp. 661-681, 2003.

[15] Tang, Z., Evaluating the capacities of local jurisdictions' coastal zone land use planning in California. Ocean and Coastal Management, 51(7), pp. 544-555, $2008 \mathrm{~b}$.

[16] Tang, Z., Bright, E. \& Brody, S.D., Evaluating California local land use plans' environmental impact reports. Environmental Impact Assessment Review, 29, pp. 96-106, 2008c.

[17] Tang, Z. \& Brody, S.D., Link planning theories with the factors influencing local environmental plan quality. Environmental and Planning B: Planning and Design, 36, pp. 522-537, 2009.

[18] Berke, P.R., Roenigk, D., Kaiser, E. \& Burby, R., Enhancing plan quality: evaluating the role of state planning mandates for natural hazard mitigation. Journal of Environmental Planning and Management, 39, pp. 79-96, 1996.

[19] Norton, R.K., Local commitment to state-mandated planning in coastal North Carolina. Journal of Planning Education and Research, 25(2), pp. 149-171, 2005.

[20] Scott, D. \& Willits, F.K., Environmental attitudes and behavior. Environmental Behavior, 26(2), pp. 239-261, 1994.

[21] Van Liere, K.D. \& Dunlap, R.E., Environmental concern-does it make a difference how it's measured? Environmental Behavior, 13, pp. 651-676, 1981.

[22] Guagano, G.A. \& Markee, N., Regional differences in the sociodemographic determinants of environmental concern. Population and Environment, 17, pp. 135-149, 1995.

[23] Randolph, J. \& Bauer, M., Improving environmental decision-making through collaborative methods. Review of Policy Research, 16(3-4), pp. 168-191, 1999.

[24] Scholz, J.T. \& Stiftel, B. (eds), Adaptive Governance and Water Conflict: New Institutions for Collaborative Planning, Resources for the Future: Washington DC, 2005.

[25] Kato, S. \& Ahern, J., 'Learning by doing': adaptive planning as a strategy to address uncertainty in planning. Journal of Environmental Planning and Management, 51, pp. 543-559, 2008.

[26] Albrechts, L., Bridge the Gap: From Spatial Planning to Strategic Projects. European Planning Studies, 14(10), pp. 1487-1500, 2006. 
[27] Brody, S.D., Highfield, W. \& Carrasco, V., Measuring the collaborative planning capabilities of local jurisdictions to manage ecological systems in southern Florida. Landscape and Urban Planning, 69, pp. 33-50, 2004.

[28] Duvall, J. \& Zint, M., A review of research on the effectiveness of environmental education in promoting intergenerational learning. The Journal of Environmental Education, 38(4), pp. 14-24, 2007.

[29] Lindell, M.K. \& Meier, M.J., Effectiveness of community planning for toxic chemical emergencies. Journal of the American Planning Association, 60(2), pp. 222-234, 1994.

[30] Franks, T., Capacity building and institutional development: reflections on water. Public Administration and Development, 19, pp. 51-61, 1999.

[31] Ridder, D. \& Pahl-Wostl, C., Participatory integrated assessment in local level planning. Regional Environmental Change, 5, pp. 188-196, 2005.

[32] Smith, D.W. \& Biswas, N., Environmental engineering education in Canada. Journal of Environmental Engineering and Science, 1, pp. 1-7, 2002.

[33] Kartez, J.D. \& Lindell, M.K., Planning for uncertainty: the case of local disaster planning. Journal of the American Planning Association, 53(4), pp. 487-489, 1987.

[34] Margerum, R.D. \& Born, S.M., Integrated environmental management: moving from theory to practice. Journal of Environmental Planning and Management, 38, pp. 371-392, 1995.

[35] Bruins, H.J. \& Lithwick, H. (eds), The Arid Frontier: Interactive Management of Environment and Development, Kluwer: Dordrecht, The Netherlands, 1998.

[36] Lein, J.K., Integrated Environmental Planning, Blackwell: Oxford, 2003.

[37] Rahaman, M.M. \& Varis, O., Integrated water resources management: evolution, prospects and future challenges. Sustainability: Science, Practice, \& Policy, 1(1), pp. 15-21, 2005.

[38] Slocombe, D.S., Environmental planning, ecosystem science, and ecosystem approaches for integrating environment and development. Environmental Management, 17, pp. 289-303, 1993a.

[39] Leitão, A.B. \& Ahern, J., Applying landscape ecological concepts and metrics in sustainable landscape planning. Landscape and Urban Planning, 59, pp. 65-93, 2002.

[40] Slocombe, D.S., Implementing ecosystem-base management. Bioscience, 43, pp. 612-622, 1993b.

[41] Brody, S.D., Are we learning to make better plans? A longitudinal analysis of plan quality associated with natural hazards. Journal of Planning Education and Research, 23, pp. 191-201, 2003.

[42] Grumbine, R.E., Reflections on "What is ecosystem management?" Conservation Biology, 11, pp. 41-47, 1997.

[43] Holling, C.S. (ed), Adaptive Environmental Assessment and Management, John Wiley: New York, 1978.

[44] Holling, C.S., What barriers? What bridges? Barriers and Bridges to the Renewal of Ecosystems and Institutions, ed. L. Gunderson, C.S. Holling \& S.S. Light, Columbia University Press: New York, pp. 3-34, 1995.

[45] Lessard, G., An adaptive approach to planning and decision-making. Landscape and Urban Planning, 40, pp. 81-87, 1998.

[46] Selin, S. \& Chavez, D., Developing a collaborative model for environmental planning and management. Environmental Management, 19, pp. 189-195, 1995.

[47] Szaro, R.C., Sexton, W.T. \& Malone, C.R., The emergence of ecosystem management as a tool for meeting people's needs and sustaining ecosystems. Landscape and Urban Planning, 40(1-3), pp. 1-7, 1998.

[48] Halprin, L., Strategies for successful teamwork. Landscape Architecture, 79(4), p. 128, 1989. 